\title{
Single nucleotide polymorphisms in the HIF-1 $\alpha$ gene and chemoradiotherapy of locally advanced rectal cancer
}

\author{
BIRGITTE MAYLAND HAVELUND ${ }^{1,2}$, KAREN-LISE GARM SPINDLER ${ }^{1,2}$, JOHN PLOEN $^{1}$, \\ RIKKE FREDSLUND ANDERSEN $^{3}$ and ANDERS JAKOBSEN ${ }^{1,2}$ \\ ${ }^{1}$ Department of Oncology, Vejle Hospital, Vejle $7100 ;{ }^{2}$ Faculty of Health Sciences, \\ Institute of Regional Health Services Research, University of Southern Denmark, Odense 5000; \\ ${ }^{3}$ Department of Biochemistry, Vejle Hospital, Vejle 7100, Denmark
}

Received March 22, 2012; Accepted July 3, 2012

DOI: $10.3892 / \mathrm{ol} .2012 .837$

\begin{abstract}
The aim of this study was to investigate the predictive impact of polymorphisms in the HIF-1 $\alpha$ gene on the response to chemoradiotherapy (CRT) in rectal cancer. This study included two cohorts of patients with locally advanced rectal cancer receiving long-course CRT. The HIF- $1 \alpha$ C1772T (rs11549465), G1790A (rs11549467) and c*191T>C (rs2057482) polymorphisms were investigated in the test cohort $(n=65)$, and HIF-1 $\alpha \mathrm{c}^{*} 191 \mathrm{~T}>\mathrm{C}$ was analysed in the validation cohort $(\mathrm{n}=198)$. No correlations were identified between the polymorphisms and clinicopathological factors. The HIF-1 $\alpha$ C1772T and HIF-1 $\alpha$ G1790A polymorphisms demonstrated no correlation with tumour response to CRT in the test cohort. The HIF-1 $\alpha$ c*191T>C CC genotype was marginally associated with a higher rate of complete tumour response $(\mathrm{P}=0.05)$ in the test cohort, while the HIF-1 $\alpha \mathrm{c}^{*} 191 \mathrm{~T}>\mathrm{C} \mathrm{CC}$ genotype was associated with a poor tumour response $(\mathrm{P}=0.03)$ in the validation cohort. In conclusion, these results suggest that HIF-1 $\alpha$ polymorphisms have no value as predictors of response to neoadjuvant CRT in rectal cancer. The results of the HIF-1 $\alpha c^{*} 191 \mathrm{~T}>\mathrm{C}$ in two cohorts differ and emphasise the importance of biomarker validation.
\end{abstract}

\section{Introduction}

Long-course chemoradiotherapy (CRT) followed by mesorectal excision is now considered as a standard treatment for locally advanced rectal cancer. Compared with radiation alone, CRT reduces the risk of local recurrence; however, the impact on overall survival is dubious (1). CRT is only beneficial to a subgroup of patients; thus, a more efficient patient selection for the combined treatment is required. A minor group of patients experiences complete tumour response, which may be verified by pathological examination of the surgical specimens. These

Correspondence to: Mrs. Birgitte Mayland Havelund, Department of Oncology, Vejle Hospital, 25 Kabbeltoft, Vejle 7100, Denmark E-mail: birgitte.mayland.havelund@slb.regionsyddanmark.dk

Key words: chemotherapy, hypoxia-inducible factor $1 \alpha$ subunit, radiotherapy, rectal neoplasm, single nucleotide polymorphism patients may avoid surgery involving a permanent stoma $(2,3)$. The current situation requires markers which are able to predict the complete tumour response with regards to patient selection.

Several markers of potentially predictive value have been studied, but to date, none have passed clinical validation, which is a hallmark for clinical routine application. Tumour hypoxia is a well-established phenomenon in the development of malignant tumours (4), and the importance of hypoxia to the effect of radiotherapy has been acknowledged for decades (5). Markers associated with hypoxia are evident candidates as predictors of response to CRT.

Hypoxia-inducible factor 1 (HIF-1) is a central protein involved in the cellular adaption to hypoxia. HIF-1 is a heterodimeric transcription factor consisting of HIF-1 $\alpha$ and HIF- $1 \beta$ subunits (6), which induce the transcription of numerous genes that are necessary for the cellular response to hypoxia (7). Oxygen tension is essential for the activation of HIF-1. The presence of oxygen leads to the degradation of HIF-1 $\alpha$, while hypoxic conditions allow HIF-1 $\alpha$ to bind to HIF-1 $\beta$ and become an active transcription-inducer (8). HIF-1 $\alpha$ has been associated with aggressive tumour growth (4) and poor prognosis in several types of cancer, including colorectal cancer (9).

HIF-1 is an important mediator of hypoxia-induced radioresistance, and studies have demonstrated that cell lines with impaired HIF-1 activation ability are more sensitive to radiotherapy compared with cells with intact HIF-1 activation ability (10-12). Additionally, the in vitro response of tumour cells to 5-fluorouracil (5FU) appears to be dependent on HIF-1 (13).

Only a small number of studies have investigated the possible predictive value of HIF-1 $\alpha$ in CRT of rectal cancer. In a previous study, we identified no correlation between immunohistochemical (IHC) expression of the HIF-1 $\alpha$ protein and tumour response (14). Another study observed an association between the staining intensity of HIF-1 $\alpha$ and poor response; however, this association was not significant when comparing HIF- $1 \alpha$ positive tumours and HIF- $1 \alpha$ negative tumours (15). The gene expression of HIF-1 $\alpha$ was studied by Toiyama et al who identified an association between high HIF-1 $\alpha$ gene expression and poor tumour response following short-course CRT (16), while Saigusa et al identified no correlation between 
HIF-1 $\alpha$ gene expression and tumour response (17). To date, the results presented of HIF-1 $\alpha$ protein and gene expression in relation to rectal cancer CRT have been inconclusive. The role of germline polymorphisms in the HIF-1 $\alpha$ gene in relation to CRT remain to be explored.

The HIF-1 $\alpha$ gene is located on chromosome 14 and a number of single nucleotide polymorphisms (SNPs) have been identified in the HIF-1 $\alpha$ gene. The most frequently investigated polymorphisms are the C1772T (rs11549465), which comprises an amino acid change from proline to serine at position 582, and the G1790A (rs11549467), which results in the substitution of alanine with threonine at position 588 . These polymorphic variants have demonstrated functional importance by increasing the transcriptional activity in vitro under normoxic and hypoxic conditions, and have been associated with increased microvessel density in patients with head and neck cancer (18).

Few studies have suggested a correlation between the above mentioned polymorphisms and the risk of colorectal cancer $(19,20)$; while one study demonstrated an association between HIF-1 $\alpha \mathrm{c}^{*} 191 \mathrm{~T}>\mathrm{C}$ (rs2057482) and the risk of rectal cancer (21). No previous studies have investigated the possible importance of these polymorphisms for rectal cancer CRT.

The aim of this study was to investigate the predictive impact of germline C1772T, G1790A and c*191T>C polymorphisms in the HIF-1 $\alpha$ gene on the response to CRT in locally advanced rectal cancer.

\section{Patients and methods}

Patients. The study included two cohorts treated with long-course CRT at the Department of Oncology (Vejle Hospital, Denmark). Inclusion criteria were patients with T3-T4 N0-N2 M0 histopathologically verified adenocarcinoma of the rectum, located $<10 \mathrm{~cm}$ from the anal verge and with a distance of $<5 \mathrm{~mm}$ to the mesorectal fascia. Pre-treatment staging was performed based on clinical examinations and magnetic resonance imaging (MRI) of the pelvis. Furthermore, computerised tomography (CT) of the chest and abdomen, or a chest X-ray and ultrasound of the liver were conducted to exclude distant metastases. Patients with available archival blood samples were included in this study.

The test cohort included 65 patients who were treated according to two previously published studies $(22,23)$ with long-course CRT between 2002 and 2005, comprising conventional radiotherapy of $60 \mathrm{~Gy} / 30$ fractions and supplemented by a brachytherapy boost of $5 \mathrm{~Gy}$. Concomitant chemotherapy consisting of $300 \mathrm{mg} / \mathrm{m}^{2}$ UFT (uracil-tegafur; molar ratio 4:1) and $22.5 \mathrm{mg}$ isovorin was administered to patients on treatment days.

The validation cohort included 203 patients who were treated according to a phase III randomised study between 2005 and 2009, comprising conventional CRT of $50.4 \mathrm{~Gy} / 28 \mathrm{frac}-$ tions with or without $10 \mathrm{~Gy} / 2$ fractions of brachytherapy. Concomitant chemotherapy was administered as previously described (24) Patient consent was obtained prior to inclusion in the studies (22-24) which were approved by the local ethics committee of The Regional Scientific Ethical Committee for Southern Denmark.
Table I. Clinicopathological parameters of rectal cancer patients.

\begin{tabular}{|c|c|c|c|}
\hline $\begin{array}{l}\text { Clinicopathological } \\
\text { parameters }\end{array}$ & $\begin{array}{c}\text { Test } \\
\text { cohort, } \\
\text { n }(\%)\end{array}$ & $\begin{array}{c}\text { Validation } \\
\text { cohort, } \\
\text { n }(\%)\end{array}$ & P-value \\
\hline \multicolumn{4}{|l|}{ Gender } \\
\hline Male & $45(69)$ & $126(62)$ & \multirow[t]{2}{*}{ NS } \\
\hline Female & $20(31)$ & $77(38)$ & \\
\hline \multicolumn{4}{|l|}{ Age (years) } \\
\hline Median & 63.4 & 63.3 & \\
\hline Range & $40.4-77.7$ & $35.5-78.8$ & \\
\hline \multicolumn{4}{|l|}{ cT classification } \\
\hline 3 & $62(95)$ & $168(83)$ & \multirow[t]{2}{*}{0.01} \\
\hline 4 & $3(5)$ & $35(17)$ & \\
\hline \multicolumn{4}{|l|}{$\mathrm{cN}$ classification } \\
\hline- & $18(28)$ & $23(11)$ & \multirow[t]{2}{*}{0.003} \\
\hline+ & $47(72)$ & $180(89)$ & \\
\hline \multicolumn{4}{|l|}{ TRG } \\
\hline 1 & 19 (29) & 39 (19) & \multirow[t]{4}{*}{$\mathrm{NS}^{\mathrm{a}}$} \\
\hline 2 & $15(23)$ & $28(14)$ & \\
\hline 3 & $29(45)$ & $120(59)$ & \\
\hline 4 & $2(3)$ & $16(8)$ & \\
\hline \multicolumn{4}{|l|}{ ypN classification } \\
\hline- & $48(74)$ & $138(68)$ & \multirow[t]{2}{*}{ NS } \\
\hline+ & $17(26)$ & $65(32)$ & \\
\hline \multicolumn{4}{|c|}{ CPR (TRG 1 and ypN0) } \\
\hline Yes & $16(25)$ & $35(17)$ & \multirow[t]{2}{*}{ NS } \\
\hline No & $49(75)$ & $168(83)$ & \\
\hline Total & 65 & 203 & \\
\hline
\end{tabular}

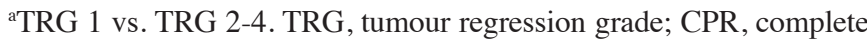
pathological response; NS, not significant $(\mathrm{P}>0.05)$.

Response evaluation. Total mesorectal excision surgery was scheduled 8 weeks following the end of CRT. Pathological response was evaluated in the surgical specimens according to Mandard's Tumour Regression Grade (TRG) (25). The endpoints of this study were complete tumour response, defined as the absence of viable residual tumour cells in the resected surgical specimens (TRG 1) and complete pathological response (CPR) defined as TRG 1 combined with no lymph node metastases (ypT0 and ypN0).

Analysis of SNPs. The investigated SNPs were selected as potentially clinically relevant polymorphisms based on previous studies (18-21,26-28). Genomic DNA was purified from whole blood using the NucloeSpin ${ }^{\circledR}$ Tissue method according to the manufacturer's instructions (NucleoSpin Tissue, Macherey-Nagel, Germany; Feb 2001/Rev. 02), or the Maxwell robot using $300 \mu \mathrm{l}$ whole blood (elution was performed in $350 \mu \mathrm{l}$ ) and the Maxwell ${ }^{\circledR} 16$ Blood DNA purification kit (AS1010; Promega, Madison, WI, USA), according to the manufacturer's instructions. 
Table II. Distribution of the HIF-1 $\alpha$ polymorphisms and the various genotypes.

\begin{tabular}{|c|c|c|c|c|}
\hline \multirow[b]{2}{*}{ HIF-1 $\alpha$ polymorphisms } & \multicolumn{2}{|c|}{ Test cohort } & \multicolumn{2}{|c|}{ Validation cohort } \\
\hline & $\mathrm{n}$ & $\%(95 \% \mathrm{CI})$ & $\mathrm{n}$ & $\%(95 \% \mathrm{CI})$ \\
\hline \multicolumn{5}{|l|}{ HIF- $1 \alpha c^{*} 191 T>C$} \\
\hline $\mathrm{CC}$ & 51 & $78(67-87)$ & 153 & $75(69-81)$ \\
\hline $\mathrm{CT}$ & 13 & $20(12-31)$ & 41 & $20(15-26)$ \\
\hline TT & 1 & $2(0.3-8)$ & 4 & $2(1-5)$ \\
\hline ND & & & 5 & 2 \\
\hline \multicolumn{5}{|l|}{ HIF- $1 \alpha \mathrm{C} 1772 \mathrm{~T}$} \\
\hline $\mathrm{CC}$ & 57 & $88(78-94)$ & & \\
\hline $\mathrm{CT}$ & 8 & $12(6-22)$ & & \\
\hline TT & 0 & & & \\
\hline \multicolumn{5}{|l|}{ HIF- $1 \alpha$ G1790A } \\
\hline GG & 64 & $98(92-100)$ & & \\
\hline GA & 1 & $2(0.3-8)$ & & \\
\hline AA & 0 & & & \\
\hline Total & 65 & & 203 & \\
\hline
\end{tabular}

Sum of the percentages does not always equal $100 \%$ due to the rounding of data. HIF-1 1 , hypoxia-inducible factor- $1 \alpha$; CI, confidence interval; $\mathrm{ND}$, not determined.

In the test cohort, the SNP analyses were conducted in-house. The HIF-1 $\alpha c^{*} 191 \mathrm{~T}>\mathrm{C}$ was analysed using the Taqman assay (c_8549084_20) with $2 \mu \mathrm{l}$ DNA and genotyping master mix in a total volume of $20 \mu \mathrm{l}$, using the $7900 \mathrm{HT}$ Real-Time polymerase chain reaction (PCR) system (Applied Biosystems, Foster City, CA, USA) on a standard programme of genotyping.

The HIF-1 $\alpha$ C1772T and G1790A were analysed by sequencing. Initially, PCR was performed with $2 \mu 1 \mathrm{DNA}$, $0.5 \mu \mathrm{M}$ primer, $2.0 \mathrm{mM} \mathrm{MgCl}{ }_{2}, 0.2 \mathrm{mM}$ deoxyribonucleotide triphosphate (dNTP) and 0.04 units Taq Gold with buffer (Applied Biosystems), in a total volume of $25 \mu \mathrm{l}$ with cycling conditions as follows: $95^{\circ} \mathrm{C}$ for $10 \mathrm{~min}$, and 40 cycles at $95^{\circ} \mathrm{C}$ for $40 \mathrm{sec}, 54^{\circ} \mathrm{C}$ for $40 \mathrm{sec}$ and $72^{\circ} \mathrm{C}$ for $40 \mathrm{sec}$, followed by $72^{\circ} \mathrm{C}$ for $10 \mathrm{~min}$. The PCR products were treated with ExoSAP-IT (USB Corp., Cleveland, OH, USA), to remove unused primers and nucleotides. PCR sequencing was then conducted with $1 \mu \mathrm{l}$ PCR product, $1.5 \mu \mathrm{l}$ Big Dye sequencing buffer, $1 \mu \mathrm{l}$ terminator RR mix, and $1 \mu 11.6 \mu \mathrm{M}$ forward or reverse primer, in a total volume of $10 \mu \mathrm{l}$ with cycling conditions as follows: $96^{\circ} \mathrm{C}$ for $1 \mathrm{~min}$, and 25 cycles at $96^{\circ} \mathrm{C}$ for $10 \mathrm{sec}, 50^{\circ} \mathrm{C}$ for $5 \mathrm{sec}$ and $60^{\circ} \mathrm{C}$ for $4 \mathrm{~min}$.

The primers (forward, 5'-GAC TTG GAG ATG TTA GCT CCC TA-3'; reverse, 5'-TTC TTG TAT TTG AGT CTG CTG GA-3') were designed in-house. After $45 \mu \mathrm{l}$ SAM solution and $10 \mu \mathrm{l}$ Big Dye Terminator were added to the $10 \mu \mathrm{l}$ sequencing PCR product, the sequencing product was analysed using a 3130 Genetic Analyzer (Applied Biosystems). Sequences were analysed using Sequencing Analysis Software version 5.2 (Applied Biosystems). In each method, controls were analysed alongside the samples.

In the validation cohort, purified DNA was sent to KBioscience (Hoddesdon, Hertfordshire, UK; http://www. kbioscience.co.uk) who conducted the SNP genotyping using a KASPar genotyping system, designed and validated by KBioscience. Data were inspected using their SNPviewer PC tool.

Statistical analysis. Fisher's exact test was used to analyse the association between clinicopathological parameters, TRG and the polymorphisms, as well as the differences in these parameters between the two cohorts. Confidence intervals (CIs) of the proportions of polymorphisms were calculated using the Wilson score method. All tests were two-sided and $\mathrm{P}<0.05$ was considered to indicate a statistically significant difference. NCSS 2007 statistical software (NCSS, Kaysville, UT, USA) was used for all analyses.

\section{Results}

Patient characteristics. Clinicopathological characteristics of the two cohorts are presented in Table I. The majority of patients in both cohorts had a T3 tumour, while there was a higher frequency of T4 tumours in the validation cohort $(\mathrm{P}=0.01)$. The rate of patients without clinical lymph node metastases also varied $(\mathrm{P}=0.003)$, but there was no difference with regard to complete tumour response (TRG 1) or frequency of CPR between the two cohorts.

Polymorphisms. HIF-1 $\alpha$ c*191T $>$ C, HIF- $1 \alpha$ C1772T and HIF-1 $\alpha$ G1790A polymorphisms were analysed in 65 patients in the test cohort, and the HIF-1 $\alpha \mathrm{c}^{*} 191 \mathrm{~T}>\mathrm{C}$ polymorphism was successfully analysed in 198 of the 203 patients in the validation cohort.

The distribution of the three polymorphisms in the HIF1 $\alpha$ gene is shown in Table II. All polymorphisms were in agreement 
Table III. TRG 1 and CPR according to HIF-1 $\alpha \mathrm{c}^{*} 191 \mathrm{~T}>\mathrm{C}$.

\begin{tabular}{|c|c|c|c|c|c|c|c|c|c|c|}
\hline \multirow{2}{*}{$\begin{array}{l}\text { Polymorphism and } \\
\text { genotype }\end{array}$} & \multicolumn{2}{|c|}{ TRG 1} & \multicolumn{2}{|c|}{ TRG 2-4 } & \multirow[b]{2}{*}{ P-value } & \multicolumn{2}{|c|}{$\mathrm{CPR}^{+}$} & \multicolumn{2}{|c|}{$\mathrm{CPR}^{-}$} & \multirow[b]{2}{*}{ P-value } \\
\hline & $\mathrm{n}$ & $\%$ & $\mathrm{n}$ & $\%$ & & $\mathrm{n}$ & $\%$ & $\mathrm{n}$ & $\%$ & \\
\hline \multicolumn{11}{|l|}{ Test cohort } \\
\hline HIF-1 $\alpha c^{*} 191 T>C$ CC & 18 & 35 & 33 & 65 & 0.05 & 15 & 29 & 36 & 71 & 0.16 \\
\hline HIF-1 $\alpha c^{*} 191 T>C$ CT/TT & 1 & 7 & 13 & 93 & & 1 & 7 & 13 & 93 & \\
\hline Total & 19 & & 46 & & & 16 & & 49 & & \\
\hline \multicolumn{11}{|l|}{ Validation cohort } \\
\hline HIF- $1 \alpha c^{*} 191 T>C$ CC & 25 & 16 & 128 & 84 & 0.03 & 24 & 16 & 129 & 84 & 0.19 \\
\hline HIF-1 $\alpha \mathrm{c}^{*} 191 \mathrm{~T}>\mathrm{C} \mathrm{CT} / \mathrm{TT}$ & 14 & 31 & 31 & 69 & & 11 & 24 & 34 & 76 & \\
\hline Total & 39 & & 159 & & & 35 & & 163 & & \\
\hline
\end{tabular}

TRG, tumour regression grade; CPR, complete pathological response; HIF-1 $\alpha$, hypoxia-inducible factor-1 $\alpha$.

with the Hardy Weinberg equilibrium. The homozygous TT genotype was rare in the HIF-1 $\alpha \mathrm{c}^{*} 191 \mathrm{~T}>\mathrm{C}$ and HIF-1 $\alpha \mathrm{C} 1772 \mathrm{~T}$ polymorphisms. The same applied to the GA and AA genotypes of the HIF-1 $\alpha$ G1790A polymorphism. No association was identified between the three polymorphisms and clinicopathological factors. Additionally, there was no correlation between the HIF-1 $\alpha$ C1772T or HIF-1 $\alpha$ G1790A polymorphism and response to CRT as measured by TRG and CPR in the test cohort, and consequently they were not analysed in the validation cohort.

Table III shows the association of the HIF-1 $\alpha c^{*} 191$ T $>C$ polymorphism with TRG and CPR. In the test cohort, a high rate of complete tumour regression was observed in patients with the CC homozygous genotype (35\%) compared with the CT/TT genotype (7\%) $(\mathrm{P}=0.05)$. Similarly, CPR was observed in 29 and $7 \%$ of patients with $\mathrm{CC}$ and $\mathrm{CT} / \mathrm{TT}$ genotype, respectively; however, this was not significant $(\mathrm{P}=0.16)$. In the validation cohort there appeared to be a statistically significantly lower rate of TRG 1 in patients with the CC genotype (16\%) compared with the CT/TT genotype (31\%; $\mathrm{P}=0.03)$. Similarly, CPR was observed in 16 and $24 \%$ of patients with the $\mathrm{CC}$ and $\mathrm{CT} / \mathrm{TT}$ genotype, respectively; however, this was not significant $(\mathrm{P}=0.19)$.

\section{Discussion}

Numerous biomarkers have been studied in the search for a prediction of CRT response in rectal cancer. To date, none have proven to be valid for clinical application. SNPs are attractive due to their stable nature and inexpensive analysis costs. Additionally, blood cells are easily accessible material.

To the best of our knowledge, the polymorphisms of the HIF-1 $\alpha$ gene have not been studied with regard to CRT; however, HIF-1 $\alpha$ protein expression has been subject to investigation in a number of malignant tumour types. In patients with head and neck cancer, previous studies have indicated a predictive importance of IHC HIF-1 $\alpha$ protein expression in relation to radiotherapy (29-31), which translated into poor survival. Similarly, IHC HIF-1 $\alpha$ expression has been associated with poor outcome following radical radiotherapy in patients with cancer of the cervix uteri $(32,33)$.
Based on previous studies, it is justified to investigate the possible predictive value of HIF-1 $\alpha$ in CRT of rectal cancer. However, the few studies on IHC expression of HIF-1 $\alpha$ and tumour response, including recent data from our own group, have revealed conflicting results, and the same applies to studies investigating HIF-1 $\alpha$ gene expression levels of the marker (14-17). Therefore, in the present study, we investigated polymorphisms of the HIF- $\alpha$ gene in patients with rectal cancer.

In contrast to previous data suggesting a correlation between HIF-1 $\alpha$ polymorphisms and clinicopathological parameters in colorectal cancer, we did not identify a correlation between the HIF-1 $\alpha$ polymorphisms and any of the pretreatment parameters (26,28). Knechtel et al reported that the HIF-1 $\alpha$ G1790A GA/ AA genotype was associated with localisation in the rectum and a higher T category (28); however, similar to Kang et al, the authors identified no correlation between HIF-1 $\alpha$ C1772T and clinicopathological parameters (19). With a small HIF-1 $\alpha$ G1790A GA/AA frequency of 11/341 in their population and $1 / 65$ in our cohort, it is difficult to make a qualified comparison. Fransen et al identified an association between ulcerative tumours and the variant allele of the HIF-1 $\alpha$ C1772T or HIF-1 $\alpha$ G1790A in 198 CRC patients; however, no correlation between the other clinicopathological parameters was observed (26).

In the present study, we identified a marginal association between T-containing genotypes of HIF-1 $\alpha \mathrm{c}^{*} 191 \mathrm{~T}>\mathrm{C}$ and poor response to CRT in the test cohort. However, this could not be confirmed in the validation cohort, which demonstrated a significantly opposing effect. The results presented in this study underline the importance of validation studies. The literature on biomarkers is characterised by a high number of small 'positive' studies, which are never validated in new prospective patient materials, and the risk of small 'positive' studies demonstrating a false positive is extremely high (34).

The two cohorts in this study varied with regards to the pre-treatment $\mathrm{cT} / \mathrm{cN}$ category and the type of radiotherapy administered. The test cohort included patients from two previously published studies of which one solely included T3 tumours. This explains the differences in the cT category. Additionally, a difference in lymph node metastasis pre-treatment evaluation was observed between the two cohorts, but 
no difference was observed in the lymph node metastasis post-treatment pathological evaluation. All patients of the test cohort received brachytherapy, while only half of the patients in the validation cohort received brachytherapy. However, in the validation cohort there was no difference in the association of the polymorphism and the response to CRT between patients receiving brachytherapy and those who did not. These minor differences between the cohorts are unlikely to explain the various results on tumour response in the two cohorts. Therefore, a clinically relevant predictive role of the polymorphisms with regards to neoadjuvant CRT of rectal cancer is dubious.

In conclusion, we were unable to find any predictive value of the HIF- $1 \alpha$ C1772T, HIF- $1 \alpha$ G1790A and HIF- $1 \alpha c^{*} 191$ T $>$ C polymorphisms with regards to tumour response following neoadjuvant CRT of locally advanced rectal cancer.

\section{Acknowledgements}

The authors are grateful to Tina Brandt Christensen and Lone Hartmann Hansen for their excellent efforts in the laboratory, and Lone Frischknecht who designed the primers and optimised the sequencing analyses. This study was supported by the Lundbeck Foundation Centre for Interventional Research in Radiation Oncology (CIRRO), and the Desiree and Niels Ydes Foundation.

\section{References}

1. Fleming FJ, Pahlman L and Monson JR: Neoadjuvant therapy in rectal cancer. Dis Colon Rectum 54: 901-912, 2011.

2. Habr-Gama A, Perez RO, Nadalin W, et al: Long-term results of preoperative chemoradiation for distal rectal cancer correlation between final stage and survival. J Gastrointest Surg 9: 90-99, 2005.

3. Maas M, Beets-Tan RG, Lambregts DM, et al: Wait-and-see policy for clinical complete responders after chemoradiation for rectal cancer. J Clin Oncol 29: 4633-4640, 2011.

4. Harris AL: Hypoxia - a key regulatory factor in tumour growth. Nat Rev Cancer 2: 38-47, 2002.

5. Gray LH, Conger AD, Ebert M, Hornsey S and Scott OC: The concentration of oxygen dissolved in tissues at the time of irradiation as a factor in radiotherapy. Br J Radiol 26: 638-648, 1953

6. Wang GL, Jiang BH, Rue EA and Semenza GL: Hypoxia-inducible factor 1 is a basic-helix-loop-helix-PAS heterodimer regulated by cellular $\mathrm{O}_{2}$ tension. Proc Natl Acad Sci USA 92: 5510-5514, 1995.

7. Vordermark D and Brown JM: Endogenous markers of tumour hypoxia predictors of clinical radiation resistance? Strahlenther Onkol 179: 801-811, 2003.

8. Jewell UR, Kvietikova I, Scheid A, Bauer C, Wenger RH and Gassmann M: Induction of HIF-1alpha in response to hypoxia is instantaneous. FASEB J 15: 1312-1314, 2001.

9. Semenza GL: Defining the role of hypoxia-inducible factor 1 in cancer biology and therapeutics. Oncogene 29: 625-634, 2010.

10. Unruh A, Ressel A, Mohamed HG, et al: The hypoxia-inducible factor-1 alpha is a negative factor for tumour therapy. Oncogene 22: 3213-3220, 2003.

11. Williams KJ, Telfer BA, Xenaki D, et al: Enhanced response to radiotherapy in tumours deficient in the function of hypoxia-inducible factor-1. Radiother Oncol 75: 89-98, 2005.

12. Moeller BJ and Dewhirst MW: HIF-1 and tumour radiosensitivity. Br J Cancer 95: 1-5, 2006.

13. Ravizza R, Molteni R, Gariboldi MB, Marras E, Perletti G and Monti E: Effect of HIF-1 modulation on the response of twoand three-dimensional cultures of human colon cancer cells to 5-fluorouracil. Eur J Cancer 45: 890-898, 2009.

14. Havelund BM, Sorensen FB, Lindebjerg J, Spindler KL and Jakobsen A: Pretreatment HIF-1 $\alpha$ and GLUT-1 expressions do not correlate with outcome after preoperative chemoradiotherapy in rectal cancer. Anticancer Res 31: 1559-1565, 2011.
15. Korkeila E, Jaakkola PM, Syrjanen K, Sundstrom J and Pyrhonen S: Preoperative radiotherapy downregulates the nuclear expression of hypoxia-inducible factor-1alpha in rectal cancer. Scand J Gastroenterol 45: 340-348, 2010.

16. Toiyama Y, Inoue Y, Saigusa S, et al: Gene expression profiles of epidermal growth factor receptor, vascular endothelial growth factor and hypoxia-inducible factor-1 with special reference to local responsiveness to neoadjuvant chemoradiotherapy and disease recurrence after rectal cancer surgery. Clin Oncol ( $R$ Coll Radiol) 22: 272-280, 2010.

17. Saigusa S, Tanaka K, Toiyama Y, et al: Clinical significance of CD133 and hypoxia inducible factor- $1 \alpha$ gene expression in rectal cancer after preoperative chemoradiotherapy. Clin Oncol (R Coll Radiol) 23: 323-332, 2011.

18. Tanimoto K, Yoshiga K, Eguchi H, et al: Hypoxia-inducible factor-1alpha polymorphisms associated with enhanced transactivation capacity, implying clinical significance. Carcinogenesis 24: 1779-1783, 2003.

19. Kang MJ, Jung SA, Jung JM, et al: Associations between single nucleotide polymorphisms of MMP2, VEGF, and HIF1A genes and the risk of developing colorectal cancer. Anticancer Res 31: 575-584, 2011.

20. Kuwai T, Kitadai Y, Tanaka S, et al: Single nucleotide polymorphism in the hypoxia-inducible factor-1alpha gene in colorectal carcinoma. Oncol Rep 12: 1033-1037, 2004

21. Frank B, Hoffmeister M, Klopp N, Illig T, Chang-Claude J and Brenner H: Single nucleotide polymorphisms in Wnt signaling and cell death pathway genes and susceptibility to colorectal cancer. Carcinogenesis 31: 1381-1386, 2010.

22. Jakobsen A, Mortensen JP, Bisgaard C, Lindebjerg J, Hansen JW and Rafaelsen SR: Preoperative chemoradiation of locally advanced T3 rectal cancer combined with an endorectal boost. Int J Radiat Oncol Biol Phys 64: 461-465, 2006.

23. Jakobsen A, Mortensen JP, Bisgaard C, Lindebjerg J, Rafaelsen SR and Bendtsen VO: A COX-2 inhibitor combined with chemoradiation of locally advanced rectal cancer: a phase II trial. Int J Colorectal Dis 23: 251-255, 2008.

24. Jakobsen AKM, Appelt AL, Lindebjerg J, Ploeen J, Rafaelsen SR and Vuong T: The dose-effect relationship in preoperative chemoradiation of locally advanced rectal cancer: Preliminary results of a phase III trial. J Clin Oncol (Meeting Abstracts) 29: 3512, 2011.

25. Mandard AM, Dalibard F, Mandard JC, et al: Pathologic assessment of tumour regression after preoperative chemoradiotherapy of esophageal carcinoma. Clinicopathologic correlations. Cancer 73: 2680-2686, 1994.

26. Fransén K, Fenech M, Fredrikson M, Dabrosin C and Söderkvist P: Association between ulcerative growth and hypoxia inducible factor-1alpha polymorphisms in colorectal cancer patients. Mol Carcinog 45: 833-840, 2006.

27. Fu XS, Choi E, Bubley GJ and Balk SP: Identification of hypoxia-inducible factor-1alpha (HIF-1alpha) polymorphism as a mutation in prostate cancer that prevents normoxia-induced degradation. Prostate 63: 215-221, 2005.

28. Knechtel G, Szkandera J, Stotz M, et al: Single nucleotide polymorphisms in the hypoxia-inducible factor-1 gene and colorectal cancer risk. Mol Carcinog 49: 805-809, 2010.

29. Aebersold DM, Burri P, Beer KT, Laissue J, Djonov V, Greiner RH and Semenza GL: Expression of hypoxia-inducible factor-1alpha: a novel predictive and prognostic parameter in the radiotherapy of oropharyngeal cancer. Cancer Res 61: 2911-2916, 2001.

30. Silva P, Slevin NJ, Sloan P, et al: Prognostic significance of tumour hypoxia inducible factor-1alpha expression for outcome after radiotherapy in oropharyngeal cancer. Int J Radiat Oncol Biol Phys 72: 1551-1559, 2008.

31. Schrijvers ML, van der Laan BF, de Bock GH, et al: Overexpression of intrinsic hypoxia markers HIF1alpha and CA-IX predict for local recurrence in stage T1-T2 glottic laryngeal carcinoma treated with radiotherapy. Int $\mathbf{J}$ Radiat Oncol Biol Phys 72: 161-169, 2008

32. Bachtiary B, Schindl M, Potter R, et al: Overexpression of hypoxia-inducible factor 1alpha indicates diminished response to radiotherapy and unfavorable prognosis in patients receiving radical radiotherapy for cervical cancer. Clin Cancer Res 9: 2234-2240, 2003.

33. Burri P, Djonov V, Aebersold DM, et al: Significant correlation of hypoxia-inducible factor-1alpha with treatment outcome in cervical cancer treated with radical radiotherapy. Int J Radiat Oncol Biol Phys 56: 494-501, 2003.

34. Christley RM: Power and error: Increased risk of false positive results in underpowered studies. Open Epidemiol J 3: 16-19, 2010. 